\title{
Consequentialism and Its Demands: A Representative Study
}

\section{Attila Tanyi \& Martin Bruder}

\section{The Journal of Value Inquiry}

ISSN 0022-5363

$J$ Value Inquiry

DOI 10.1007/s10790-014-9418-0
Volume 48, No. 1 (2014)

The Journal of

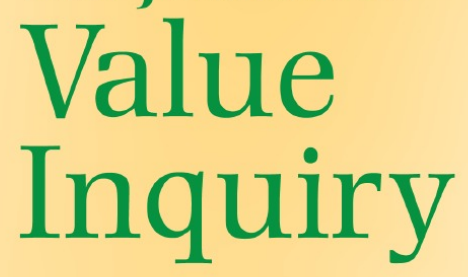

Editor-in-Chief

John Hacker-Wright

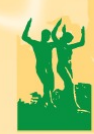

型 Springer

包 Springer 
Your article is protected by copyright and all rights are held exclusively by Springer Science +Business Media Dordrecht. This e-offprint is for personal use only and shall not be selfarchived in electronic repositories. If you wish to self-archive your article, please use the accepted manuscript version for posting on your own website. You may further deposit the accepted manuscript version in any repository, provided it is only made publicly available 12 months after official publication or later and provided acknowledgement is given to the original source of publication and a link is inserted to the published article on Springer's website. The link must be accompanied by the following text: "The final publication is available at link.springer.com". 


\title{
Consequentialism and Its Demands: A Representative Study
}

\author{
Attila Tanyi $\cdot$ Martin Bruder
}

(C) Springer Science+Business Media Dordrecht 2014

\section{The Overdemandingness Objection}

Consequentialism holds that whether an act is morally right depends only on the consequences of that act or of something related to that act, such as the motive behind the act or a general rule requiring acts of the same kind, as judged from an impersonal perspective. The paradigm case of consequentialism is utilitarianism, whose classic proponents were Jeremy Bentham, John Stuart Mill, and Henry Sidgwick. These classic utilitarians were all act-consequentialists: They held that whether an act is morally right or wrong depends only on its consequences (as opposed to the circumstances or the intrinsic nature of the act or anything that happens before the act or anything that relates to the act). They were utilitarians because they advocated consequentialism with a

\begin{abstract}
As subsequent references will show, the present paper is part of a larger project on the experimental foundations of the Overdemandingness Objection. At present, there is one other paper - 'Overdemanding Consequentialism? An Experimental Approach', under review - which takes as a starting point the same philosophical problem. However, the two papers follow very different trajectories. Whereas the latter paper investigates the basic problematic using a variety of methods and raises some doubt on whether the empirical assumption implied by OD really applies in the real word, the present paper replicates these findings and moves beyond them in several ways. First, the representative sample ensures that the findings are not limited to the particular sample of students. Second, the size of the sample allows to investigate whether there are predictable differences in the relevant intuition. Also, the present paper presents the philosophical problematic in a different way and discusses problems that are not covered in the other paper, ending with a detailed description of a novel methodological approach to investigate the status of moral intuitions.
\end{abstract}

\section{A. Tanyi}

Department of Philosophy, University of Liverpool, Liverpool, UK

\section{A. Tanyi (凶)}

Zukunftskolleg, University of Konstanz, Konstanz, Germany

e-mail: attila.tanyi@uni-konstanz.de

M. Bruder

Zukunftskolleg and Department of Psychology, University of Konstanz, Konstanz, Germany 
welfarist theory of value, that is, a theory that focuses on welfare, well-being, or happiness as the relevant consequence. And since they understood happiness in terms of the balance of the amount of pleasure over pain, they were also hedonists. In this paper our subject matter will be an objection that has originally targeted classic utilitarians, but can be employed against any form of act-consequentialism (from now on 'consequentialism', unless qualifier needed).

We call this charge the Overdemandingness Objection or OD. ${ }^{1}$ Advocates of OD make two interrelated claims. One, given how the world is, the demands of consequentialism are unreasonably high. Two, moral theories must not be unreasonable demanding. The first claim has in fact two parts. One is a theoretical claim that translates consequentialism into the requirement that one should promote the good until the point where further efforts would burden one more than it would benefit others. The other is an empirical claim about how things are in the world: that there are, e.g., high levels of poverty both internationally and, in most cases, domestically; that individual, voluntary efforts alone cannot put an end to this poverty; and that institutions aiming to do so are ineffective (among others). ${ }^{2}$ The second claim is a statement about what people intuit about an unreasonably demanding morality, namely, that it is objectionable. Most people are assumed to have this intuition because consequentialism, as the first claim details, requires them for the sake of morality to give up most or all of what they otherwise hold dear. Hence, the second claim goes, consequentialism, people think, cannot be right about its demands - no morality should go this far in putting demands on a moral agent. OD is an attempt to articulate this intuitive constraint on moral theories.

Any proper investigation into this problematic must take as its starting point the most plausible form of OD. Because one of us has argued this point in more detail elsewhere, here we will only give a brief summary of the reasoning. ${ }^{3}$ To begin with, since the notion of a moral demand encompasses three separate dimensions, OD can be given three different interpretations. The dimension of scope refers to the pervasiveness of a moral theory: to the circle of voluntary human action that the theory regards as open to moral assessment. A moral theory is overdemanding in this sense if the circle of actions open to moral assessment is intuitively too broad. ${ }^{4}$ The dimension of content deals with the stringency of a moral theory: with the amount of inconsistency between moral directives and the agent's non-moral projects. A moral theory is overdemanding in this sense if it contains requirements that, intuitively, it should not, or if it imposes intuitively unacceptable costs on the agent. ${ }^{5}$ Finally, the

\footnotetext{
${ }^{1}$ For references see Brad Hooker, 'The Demandingness Objection', in T. Chappell (ed.), The Problem of Moral Demandingness: New Philosophical Essays, (London: MacMillan, 2009), p. 162 footnote 4, and Alan Carter, 'Is Utilitarian Morality Necessarily too Demanding?', in The Problem of Moral Demandingness, pp. 163-185, as well as the works to be cited in the next section.

2 The works of Thomas Pogge are instructive in this regard. See his World Poverty and Human Rights: Cosmopolitan Responsibilities and Reforms, (Cambridge: Polity Press, 2008) and Politics as Usual: What Lies Behind the Pro-Poor Rhetoric, (Cambridge: Polity Press, 2010).

3 See Tanyi Attila, 'The Case for Authority', in S. Schleidgen (ed.), Should We Always Act morally? Essays on Overridingness, (Marburg: Tectum, 2012), pp. 159-189.

${ }^{4}$ Cf. Samuel Scheffler, Human Morality, (Oxford: Oxford University Press, 1992), Chapter 1.

5 Cf. Liam Murphy, Moral Demands in Non-Ideal Theory, (Oxford: Oxford University Press, 2000), Chapter 1.
} 
dimension of authority concerns the normative force of a moral theory: it is about the weight of moral reasons as compared to the weight of non-moral reasons. A moral theory is overdemanding in this sense if it holds that certain actions that, intuitively, we do not have decisive reason to perform, are nevertheless normatively obligatory. ${ }^{6}$

Let us now turn to the assessment of these readings. Start with a bold claim: the first two dimensions do not give us a demandingness challenge. Reducing the scope of consequentialism is unwarranted for several reasons such as the contextdependence of moral assessment: depending on context, any action, no matter how trivial it is, invites moral assessment. For example, brushing my teeth in the bathroom is such a mundane action that moral assessment does not seem to be in place. However, if someone is trying to murder my wife in an adjacent room while I am brushing my teeth and I can hear her screams and shouts for help, continued teethbrushing becomes subject to moral assessment. In short, if there is a demandingness problem with consequentialism, it is not derived from its unrestricted scope; in fact, unrestricted scope is a desirable feature of moral theories. ${ }^{7}$

At the same time, the content-based understanding of OD, though popular, is far from convincing. In particular, two recent arguments show that focusing on the overdemanding content of consequentialism may lead critics of consequentialism to miss their target. A moral requirement, argues Paul Hurley, needs the backing of reasons in order to make a demand on the agent; hence the dimension of authority is prior to the dimension of content. ${ }^{8}$ Also, the content-based reading of OD may stem from breaks with consequentialism that are prior to and independent of its demandingness. In particular, argues David Sobel, the relevant break concerns the idea that only the costs a moral theory requires the agent to bear matter morally, whereas consequentialism holds that the costs a moral theory permits to befall on agents as a result of not requiring others to prevent it, is also morally significant. Once this is acknowledged, consequentialism ceases to be overdemanding, i.e., morally problematic. ${ }^{9}$ If either of these arguments succeeds then, just like scope, content will also not provide an overdemandingness challenge.

These considerations lead to the conclusion that those who advocate OD should follow the authority dimension. Their claim should be that consequentialism is overdemanding because, while being stringent in content and pervasive in scope, our reasons to meet its requirements override other competing reasons, resulting in situations where it demands of us, with decisive force, that we do things that, intuitively, we do not have decisive reason to do. If one wants to respond to OD, therefore, one must take this most forceful interpretation of what the Objection states, and then find reasons to reject it.

\footnotetext{
${ }^{6}$ Cf. Sarah Stroud, 'Overridingness and Moral Theory', Pacific Philosophical Quarterly 79 (1998): 170-189; Douglas W. Portmore, Commonsense Consequentialism: Wherein Morality Meets Rationality, (Oxford: Oxford University Press, 2011), Chapter 2.

7 For more on this see Scheffler, Human Morality, pp. 24-25.

8 Paul Hurley, 'Does Consequentialism Make Too Many Demands?', Ethics 116 (2006), pp. 680-706.

9 David Sobel, 'The Impotence of the Demandingness Objection', Philosophers' Imprint 7 (2007), pp. $1-17$.
} 


\section{The Empirical Background of OD}

Those who advocate OD, on the reading presented above, make the following argument:

(1) Consequentialism makes demand D.

(2) According to consequentialism, we have decisive reason to meet demand D.

(3) However, intuitively, we do not have decisive reason to meet demand D.

(4) Therefore, although consequentialism holds that we have decisive reason to meet demand D, intuitively, we have no such reason.

(5) If a moral theory makes such demands, then we have reason to reject that moral theory as overdemanding.

(6) Therefore, we have reason to reject consequentialism.

This more detailed structure suggests the possible ways of responding to OD. The classic approach either denies premise (1) or rejects premise (5). ${ }^{10}$ These responses are 'classic' because they were already applied to the classical version of OD, the one that focuses on content, instead of authority. An alternative approach is to reject premise (2). The idea here would be that consequentialism either makes no claims about reasons, or even if it does, it does not hold that people have decisive reason to follow its precepts. ${ }^{11}$

All these approaches, however, have their - often much discussed - problems; it would therefore bring fresh impetus to the discussion if one approached the problematic from a different angle. Since premises (1), (2), and (5) have already received (and are receiving) thorough attention, the only remaining crucial step in the argument of OD is premise (3). Since this premise is empirical, making claims about an intuition - we call it the OD-intuition - people allegedly share, the corresponding discussion should also be partly empirical in nature.

In what follows (section 3) we will first present findings of the experimental research we have conducted on the validity of premise (3). ${ }^{12}$ The quality of the data that we will present - in that the sample is representative of the German population - is on par with the most advanced studies in experimental philosophy. On the basis

\footnotetext{
${ }^{10}$ Concerning premise (1), the strategy of denial holds that consequentialism does not make extreme demands, either because of the empirical circumstances (cf. Tim Mulgan, The Demands of Consequentialism, (Oxford: Clarendon Press, 2001)) or because of its own internal structure (e.g., Samuel Scheffler, The Rejection of Consequentialism, (Oxford: Clarendon Press, Revised edition, 1994); Michael Slote, 'Satisficing Consequentialism', in Proceedings of the Aristotelian Society, Supplementary Volume 58 (1984), pp. 139-163). Concerning premise (5), the strategy of extremism holds that not even extreme demands are objectionable (e.g., Peter Singer, 'Famine, Affluence and Morality', Philosophy and Public Affairs 1 (1972), pp. 229-243; Shelly Kagan, The Limits of Morality, (Oxford: Oxford University Press, 1989)).

11 The recent position of scalar-consequentialism opts for the first alternative. See Alastair Norcross ('Reasons Without Demands: Rethinking Rightness', in J. Dreier (ed.), Contemporary Debates in Moral Theory, (Oxford: Blackwell, 2006), pp. 38-53). The second alternative is less controversial, and several consequentialists have held it. For critical remarks see Krister Bykvist, Understanding Utilitarianism, (London: Continuum, 2010), pp. 101-102. Note further, that the position of moral rationalism holds that this is conceptually not possible; see Portmore, Commonsense Consequentialism for this claim.

${ }^{12}$ Further studies can be found in our 'Overdemanding Consequentialism?'. We say more about these other experiments in footnotes 35,40 and 41 below.
} 
of these findings we will claim that there is some reason to doubt the validity of the premise. After this, in section 4, we will discuss general objections to our argument, in particular, worries concerning the use of intuitions in moral philosophy. In the final part of our paper (section 5) we will do two things. First, we will propose an account of intuitions and on this basis sketch out a new methodology that has the potential of adequately detecting intuitions so understood. Second, we will show how considerations of virtue can have a role in experimental studies of intuitions and also offer some remarks about how the proposed methodology has to be augmented in order to take account of this development.

\section{A Representative Study}

We conducted a scenario study to investigate the validity of premise (3) in the argument for OD above. In a scenario study, participants are presented with fictitious situations and asked to assess these with regard to the moral judgments the situations invoke and the course of action they, as possible agents in the situation, anticipate to take. The study sample was representative of the German population with respect to gender, age, and level of education.

\subsection{Procedure}

In the study, participants read eight different scenarios each of which existed in four different versions. Each participant read and responded only to one version of each scenario. Each scenario outlined a morally challenging situation and offered two possible courses of action: one that, by stipulation, was in line with consequentialist demands and one that more narrowly focused on the agent's (economic) selfinterest. Similar to a scenario study we presented elsewhere we induced consequentialist demands by making it more or less attractive to act in one's selfinterest (whereby self-interest was defined such that it excluded impersonal moral interests). ${ }^{13}$ In those experimental conditions in which acting in one's own interest was rendered highly attractive, this implies that acting according to the requirements of consequentialism (i.e., deciding not to follow the attractive option) makes higher demands on an agent as compared to those conditions in which acting in one's selfinterest was rendered comparatively less attractive.

In order to clarify the notion of attractiveness, hence the notion of demand, and to see if this has an effect on the perceived demandingness of consequentialism, we made use of a distinction. We claim one choice to be more objectively attractive than an alternative choice if it is reasonable to assume that there is a (near) consensus concerning a quantitative grading of its attractiveness in the sense of "the more, the better". Economic or, more narrowly defined, financial or monetary rewards, we submit, are of this type. Accordingly, if what consequentialism requires conflicts with an objectively highly attractive reward (e.g., because it implies forgoing the chance of receiving a lot of money), then consequentialism is

$\overline{13}$ In our 'Overdemanding Consequentialism?' 
objectively demanding. Clearly, however, quantifiable differences are insufficient to describe which rewards people perceive as attractive (and correspondingly which choices are perceived as demanding). Instead different people often perceive the very same thing as differently attractive. We interpreted this observation as giving rise to subjective attractiveness. Taking again monetary rewards as an example, people feel differently about how attractive money is, hence identical monetary rewards do not have the same importance for everyone: their subjective attractiveness differs. Accordingly, the same action that requires a certain monetary sacrifice from people can be differently subjectively demanding, depending on the individual attractiveness of a certain amount of.

Drawing on own prior work and suggestions in the literature, ${ }^{14}$ we developed eight scenarios for which there was reason to believe that they elicit the intuition relevant to OD. The following basic scenarios were used (with the text of the highly demanding versions added in brackets):

- Scenario 1: It is a cold winter day. Just before you reach home, a freezing homeless person asks you for money for a warm jacket. You do not have cash on you but wonder whether you should leave your own jacket. The jacket is not special to you [high subjective demands: is your favourite jacket and has been for a number of years] and cost 30 euros [high objective demands: 180 euros].

- Scenario 2: In a few days you will be interviewed for a new job. Because of a flood disaster you - as a regular disaster relief volunteer - are asked to help in the disaster area at the time of your interview. To get the job, you will have to show up for the interview. You know that fifteen further candidates have been invited for interviews and your chances, accordingly, are relatively slim [high objective demands: You know that only one further candidate has been invited for an interview and your chances, accordingly, are relatively high]. Personally, you have substantial doubts whether the job would be a good fit for you [high subjective demands: Personally, you are absolutely certain that the job would be a good fit for you].

- Scenario 3: You own an old house in a secluded forest area in the mountains. There are plans to build an important water supply facility for a nearby children's village. The facility will be critical to the future of the village. You do not like living in your house [high subjective demands: You like living in your house a lot.]. The communal authorities ask you to leave the house and offer you the full value [high objective demands: a small fraction of the value] of the house as compensation.

- Scenario 4: At work you notice how some of your non-German co-workers are disadvantaged because of their family background. If you get engaged and stand up for your colleagues, you do not risk any negative consequences for yourself [high objective demands: you risk facing future disadvantages yourself]. You find it easy [high subjective demands: difficult], to voice your opinion when facing others.

${ }^{14}$ In particular, Bykvist, Utilitarianism, and Mulgan, Understanding Utilitarianism. 
- Scenario 5: You inherit a considerable amount of money. It is just enough to make a long holiday journey [high subjective demands: of which you have dreamed already for a long time]. At the same time, a trustworthy charity asks you to donate a small part of [high objective demands: all of] your inheritance for them to buy medication that allows the treatment of deadly diseases in African countries. Donating the money would mean that you cannot afford the journey.

- Scenario 6: You are a civil engineer and are looking for a job. You receive two offers: You can either built an orphanage in Africa receiving minimal daily allowances (the orphanage will not be built, if you do not sign up at this point). Or you can take a job in a civil engineering office in your home country. The position at home is not very well paid [high objective demands: very well paid] and the job would not satisfy you [high subjective demands: would fully satisfy you].

- Scenario 7: You are a lawyer and are asked to take on a case 'pro bono' (i.e. without pay). The case revolves around the discrimination of a tribal group in South America. Without your help, the case is lost and the group will be dislodged from their land. If you take on the case, you will lose your current job. Your current job is not very well paid [high objective demands: is very well paid] and, at a personal level, you do not experience the work as meaningful [high subjective demands: you experience the work as very meaningful].

- Scenario 8: Your company instructs you to clarify the options for building a new production facility in Ethiopia. You find out that there are no legal problems in building the factory. However, the waste water from the factory will strongly pollute the rare ground water. Environmental protectionists therefore ask you not to recommend building the factory. The company management will follow your decision. If you recommend building the factory, you will be promoted. Being promoted does not mean much to you [high subjective demands: means a lot to you] and would only imply a relatively small financial advantage [high objective demands: would imply a substantial financial advantage].

For each scenario, there were four versions: one in which both subjective and objective demands were low (see main version above), one in which subjective demands were high but objective demands low, one in which subjective demands were low and objective demands were high, and one in which both subjective and objective demands were high. Each participant was randomly assigned to one of four groups and then read the same of these four versions of each scenario. ${ }^{15}$

After having read each scenario, we asked participants three questions that were central to our analyses: First (Question 1), they indicated what they would do in such a situation (Action choice; e.g., in Scenario 1 they could "keep the jacket" or "give the jacket away" to the homeless person). Second (Question 2), they answered the question "Overall, what is the thing to do?" (Assessment of reasons; with the same answer options). Third (Question 3), they indicated what they believed morality demanded them to do (Moral judgment; again the same options).

\footnotetext{
15 Thus, the study had a 2 (Objective demands: high vs. low) $\times 2$ (Subjective demands: high vs. low) $\times 8$ (Scenario 1-8) design with repeated measures on the last factor.
} 
Most important for our analyses is Question 2 because it was designed to determine the overall assessment of reasons in this situation, hence the occurrence of the ODintuition as it appears in premise (3) in the argument of OD. The analyses below therefore focus primarily on this question.

However, the other two questions are also important, albeit for different reasons. Question 1 concerning expected actual behaviour provides some insight into the degree to which people anticipate internal (e.g., weakness of will) or external (e.g., coercion) processes interfering with the implementation of their intuition. Question 3 , concerning participants' moral assessment of the situation, was included to be able to examine whether the possible intuitive judgment that consequentialist demands are unreasonable (Question 2) is invalidated by an intuitive judgment that they are (still) moral. This is relevant because OD is an argument against consequentialism as a moral theory. But if people intuit that there is nothing morally objectionable about the unreasonable demands of consequentialism - because, we conjecture, what happens is that in their view non-moral reasons override the moral reasons - then the OD-intuition, i.e., the answer to Question 2, cannot be used to support OD. In this case, it seems, we have a moral intuition conflicting with consequentialism's alleged claim to the overridingness of its reasons, thus pushing not towards the rejection of the theory as a correct account of morality but towards rejection of its claim that its reasons are decisive.

In other words, we think that contrary to what the argument of OD suggests, there are really two intuitions that bear on the validity of the Objection. ${ }^{16}$ One is the ODintuition as it appears in premise (3) of the argument, the other is a moral intuition that concerns the overall validity of consequentialism as a moral theory. Since the two intuitions can come apart, in particular, one can hold that a consequentialist requirement is unreasonable but still take it to be morally appropriate, we need to be able to detect both intuitions. In terms of our statistical analyses, this leads to a more restrictive analysis: If the answers to Questions 2 and 3 differ in a particular way, namely, if consequentialist demands are found unreasonable but demanded by morality, then these judgments of unreasonableness are not taken to count in favour of OD. ${ }^{17}$ In our presentation, we will therefore first present the unrestricted analysis, since this is what determines how widespread the OD-intuition is, and then the restrictive one, since this is what has the final word on the validity of OD itself.

For the recruitment of this study, we cooperated with respondi AG, a company maintaining a large-scale open access panel. In this way, it was possible to recruit a large sample of online respondents $(N=1,001)$ that was largely representative of the German adult population in three key characteristics: gender, age group, and level of formal education. Normative data on these characteristics were gathered

\footnotetext{
${ }^{16}$ One might nevertheless insist that we should not consider the second moral intuition in our assessment. But if the intuition referred to in premise (3) is taken seriously, although it too conflicts with consequentialism's alleged claim to overridingness, then why not take seriously this moral intuition?

17 How about the case when the demands of consequentialism are found intuitively reasonable but not demanded by morality? Although this case is interesting - not least because one is curious why these demands are contrary to morality - it does not have relevance for us. For though the moral intuition now speaks against consequentialism, it does so on grounds other than its alleged overdemandingness. And this has no bearing on OD and hence it is not something we need to be concerned with in this paper.
} 
from official federal statistics ${ }^{18}$ and participants were recruited according to predetermined quotas. Of the 1,001 participants, 511 were female and 490 male. Age ranged from 18 to 91 with a mean of 47.6 years and a standard deviation of 18 years. All age groups (including the one 65+) were drawn proportional to their occurrence in the real population. This also explains why groups that are frequently not represented in social science studies make up a sizable proportion of our sample. For example, 303 participants were retired, 49 worked at home, 36 were unemployed, 58 were self-employed/freelancers, 84 were blue-collar workers, 321 were white-collar employees or public servants, and - compared to other studies only -119 were students (with 31 others/unidentified). Whereas employment status clearly is much closer to being representative than in most (if not any) other study in experimental moral philosophy or moral psychology, there may still be some divergence from the true distribution in the German population. In contrast, we made sure that the educational status of our sample was proportional to that of the general population. In Germany level of formal education can be characterized by the type of secondary school one attended: completing Hauptschule involves 9 grade levels (low level of formal education; $n=399$ ), completing Realschule involves 10 grade levels (medium level of formal education; $n=242$ ), and completing Gymnasium (or equivalent) involves 12-13 grade levels and is the only type of school that allows direct access to the higher education system (high level of formal education; $n=295$ ). In addition to these three levels, our sample also included representative proportions of those who did not complete school at all $(n=28)$ or who were still attending school at the time of completing the study $(n=37)$. The vast majority of the participants were native German speakers $(n=932)$ with another 66 reporting good/very good German skills and only 3 reporting German language skills of fair or worse.

\subsection{Predictions}

As argued above, proponents of OD should hold that there is a widespread intuition that moral agents do not have decisive reason to follow at least some consequentialist demands. In our study, as consequentialist demands increase, we should see an increasing number of participants that find more reason to follow the nonconsequentialist than the consequentialist course of action (Hypothesis 1). This tendency of increasing dissent with consequentialism should ultimately lead to an overwhelming majority of participants rejecting consequentialist requirements at least in the most demanding scenarios (Hypothesis 2). Finally, in line with the idea that consequentialist moral judgments require high levels of cognitive reasoning and reflection ${ }^{19}$ - capacities that are more likely to be seen in the well-educated - we expected differences between our participants such that those with lower levels of formal education should be more inclined to have intuitions that are not in line with

\footnotetext{
18 Mikrozensus 2011.

19 E.g., Joseph M. Paxton, Leo Ungar, \& Joshua D. Greene, 'Reflection and Reasoning in Moral Judgment', Cognitive Science 36 (2010), pp. 163-177.
} 
consequentialism (i.e., they should be more likely to have intuitions supporting OD; Hypothesis 3).

\subsection{Results and Discussion}

As a preliminary analysis, we tested whether our scenarios indeed elicited some noticeable level of dissent with consequentialist demands. ${ }^{20}$ The estimated means for all three questions for each of the eight scenarios (averaged across demand conditions) can be seen in Figure 1. The pattern of responses was rather consistent across scenarios. Indeed, participants revealed most dissent with consequentialism when explicitly asked for an action choice. Dissent with consequentialism was somewhat lower when asked for an assessment of reasons. This pattern hints at anticipated obstacles to implement in the real world what one actually holds to be the course of action that is favoured by an overall assessment of reasons. The fact that the assessment of reasons shows higher levels of dissent with consequentialism than the actual moral judgment indicates that our conjecture may be correct that there are actually two relevant intuitions involved: one about consequentialist demands as such and one about the overridingness of consequentialist reasons. We will follow up on this point in later analyses. Importantly, it also becomes clear from Figure 1 that Scenario 4 and Scenario 8 elicited very low levels of dissent with consequentialism. It is thus probable that these situations are not suited to trigger the intuition relevant to OD. We excluded these scenarios from all further analyses.

To test Hypothesis 1 and 2, we conducted an analysis of variance. ${ }^{21}$ Results showed that - across all six remaining scenarios - increases in both objective and subjective demands led to higher levels of dissent with consequentialism (see Figure 2). ${ }^{22}$ Thus, participants who were faced with higher demands (be they objective or subjective) were more likely to respond in line with the OD-intuition (i.e., they saw less reason to comply with consequentialist requirements). There was no interaction between the effects of objective demands and subjective demands on the level of dissent with consequentialism (i.e., the effects of objective and subjective demands were additive rather than multiplicative) ${ }^{23}$

These findings are in line Hypothesis 1: Different levels of subjective and objective demands indeed affected individual judgments. If confronted with high demands posed by consequentialism, our participants saw less reason to follow consequentialist requirements. However, the findings are inconsistent with Hypothesis 2: On average across the six scenarios, even the most demanding situations had less than $55 \%$ of the participants who indicated that they would have

\footnotetext{
${ }^{20}$ To do so, we conducted a three (for each of the three questions) 2 (Objective demands: high vs. low) $\times 2$ (Subjective demands: high vs. low) $\times 8$ (Scenario 1-8) mixed-model ANOVAs with repeated measures on the last factor and plotted the estimated marginal means.

${ }^{21} 2$ (Objective demands: high vs. low) $\times 2$ (Subjective demands: high vs. low) $\times 6$ (Scenario) with repeated measures on the last factor.

${ }^{22}$ Objective demands: $F(1,993)=40.11, p<.001, \eta_{\mathrm{p}}^{2}=.039$; subjective demands: $F(1,993)=54.88$, $p<.001, \eta_{\mathrm{p}}^{2}=.052$.

${ }^{23}$ There was no interaction between objective and subjective demands, $F(1,993)=.22, p=.64$, $\eta_{\mathrm{p}}^{2}<.000$.
} 


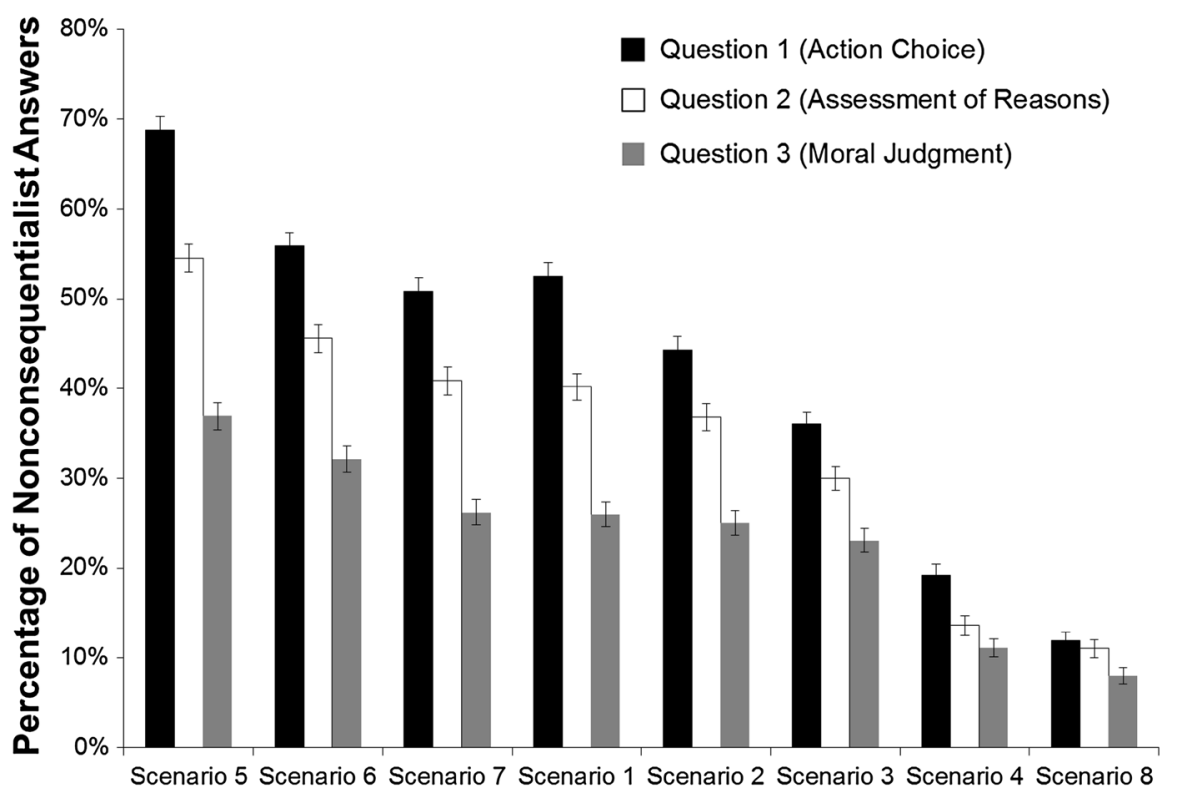

Figure 1 Percentage of nonconsequentialist answers to (a) the choice of action in the respective situation (Question 1), (b) the overall assessment of reasons for action in the situation (Question 2), and (c) the moral judgment of which action is prescribed by morality (Question 3) for each of the eight scenarios averaged across all levels of objective and subjective demands (ordered by mean response to Question 2).

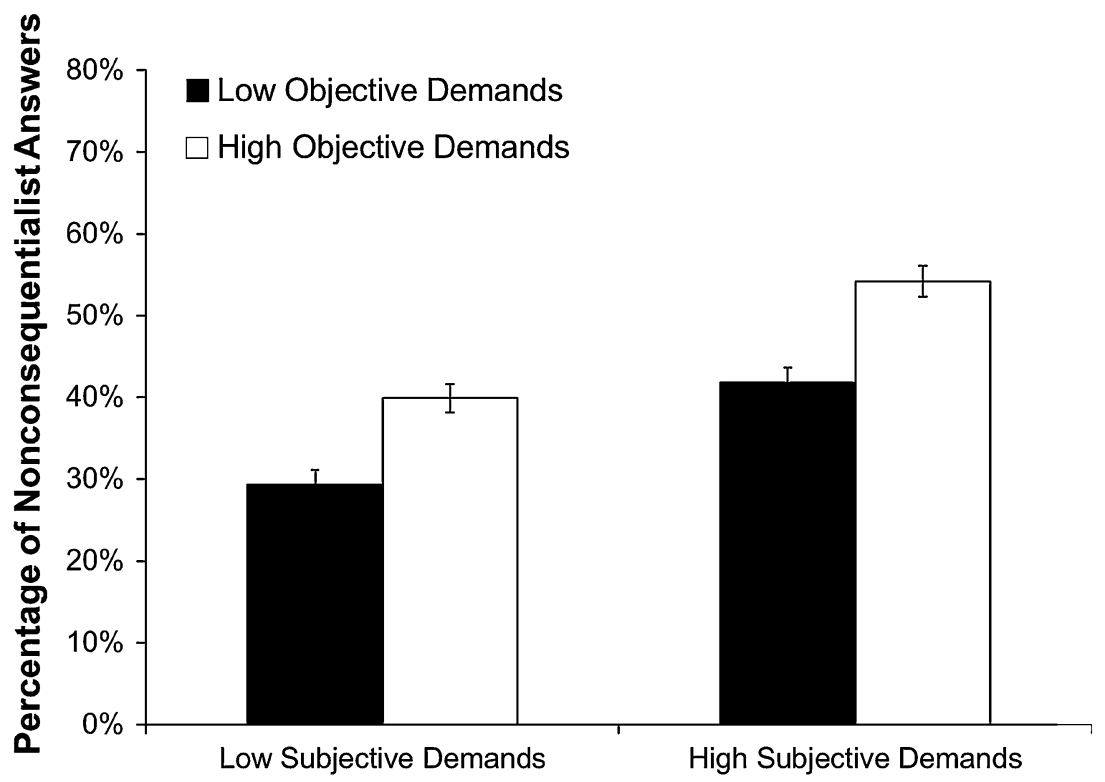

Figure 2 Percentage of nonconsequentialist answers to the overall assessment of reasons relevant to the decision averaged across the remaining six scenarios for each level of objective and subjective demands. 
more reason to follow the nonconsequentialist as compared to the consequentialist course of action. This calls into doubt premise (3) of the argument of OD insofar we found no widespread intuition concerning the unreasonable nature of some consequentialist demands.

In a next step, we included Question 3 (concerning the judgment of what morality demands one to do) in the picture. In a parallel analysis to that conducted for Question 2, Figure 3 shows that variations in objective and subjective demands do not only influence assessments of reason but also the moral judgment itself. ${ }^{24}$ That is to say, if demands are objectively or subjectively high, people are less likely to believe that the consequentialist course of action is prescribed by morality (compared to structurally identical but less demanding situations).

The divergence between responses to Question 2 and Question 3 led to a more restrictive analysis. The idea, recall, is that if the answers to Questions 2 and 3 differ in a particular way, namely, consequentialist demands are found unreasonable but are seen as being demanded by morality, the intuition concerning the unreasonable nature of the demands (Question 2) does not support OD. In the present case, this was easily quantifiable: What we did was to check, as the only constellation of answers that clearly supports OD, the percentage of those who found the consequentialist requirement not only unreasonably demanding, but also not demanded by morality.

This restrictive analysis again revealed some support for Hypothesis 1: increases in subjective (but not objective) demands led to higher levels of dissent with consequentialism. ${ }^{25}$ More important, however, when only taking into account those patterns of replies that are fully consistent with OD, the absolute level of dissent with consequentialism dropped substantially from the unrestricted analysis. On average across all scenarios, even in the most demanding condition less than $29 \%$ of our respondents gave replies that fully conformed to what proponents of OD would have to expect (see Figure 4). That is to say, even of those (in the most demanding condition) who thought that they did not have decisive reason to follow consequentialist demands, nearly half thought that the course of action demanded by consequentialism was what morality required them to do. A possible - and in our eyes probable - explanation of this finding is that, while subscribing to a consequentialist morality, they do not consider consequentialist reasons to override non-moral reasons for action (at least not in principle).

Finally, we investigated Hypothesis 3 concerning the role that formal education plays in the intuition supporting OD. To do so, we included education in the analysis. $^{26}$ As far as Question 2 was concerned, there was some evidence for a systematic influence of education on the overall assessment of reasons. On average across all conditions, those with low levels of formal education were marginally more likely to dissent with consequentialist requirements than those with medium or

\footnotetext{
${ }^{24}$ Objective demands: $\quad F(1,994)=10.71, \quad p=.001, \quad \eta_{\mathrm{p}}^{2}=.011 ; \quad$ subjective $\quad$ demands: $F(1,994)=27.55, p<.001, \eta_{\mathrm{p}}^{2}=.027$.

${ }^{25}$ Objective demands: $F(1,994)=1.23, p=.268, \eta_{\mathrm{p}}^{2}=.001$; subjective demands: $F(1,994)=4.07$, $p=.044, \eta_{\mathrm{p}}^{2}=.004$.

${ }^{26}$ We only used the three above-mentioned levels of schooling in the three-pronged German system and excluded all those with no formal education and those who were still attending school.
} 


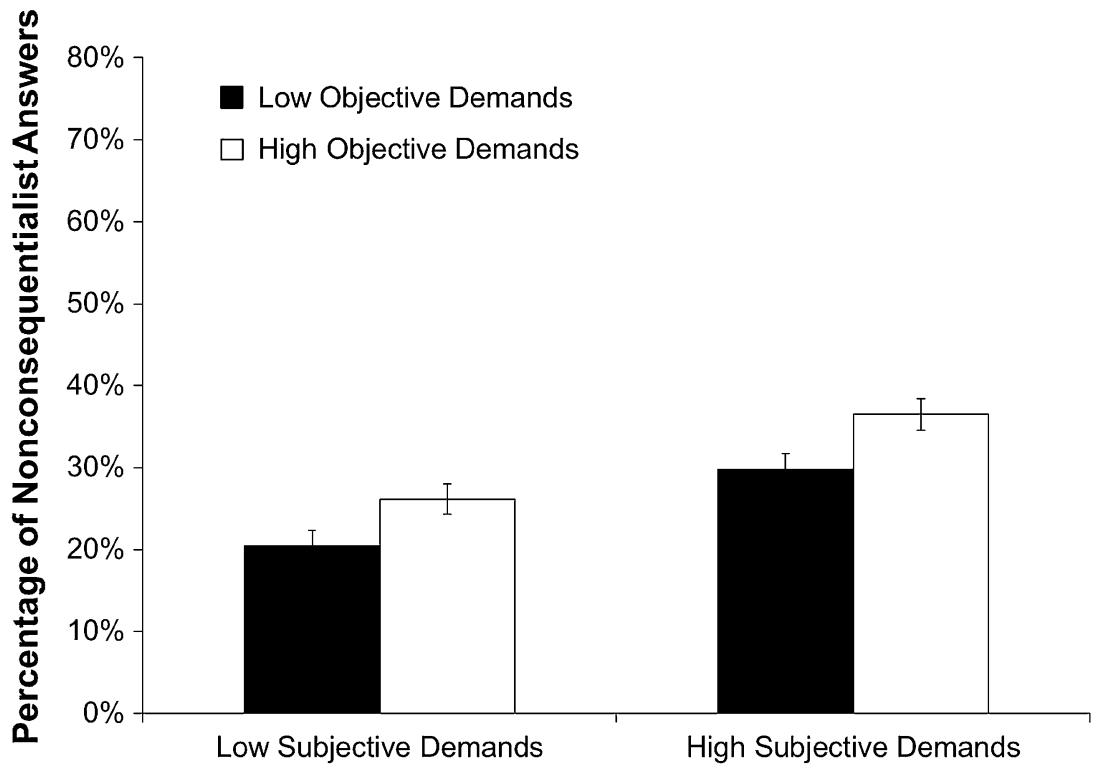

Figure 3 Percentage of nonconsequentialist answers to the judgment of what morality demands one to do in the situation averaged across the six scenarios for each level of objective and subjective demands.

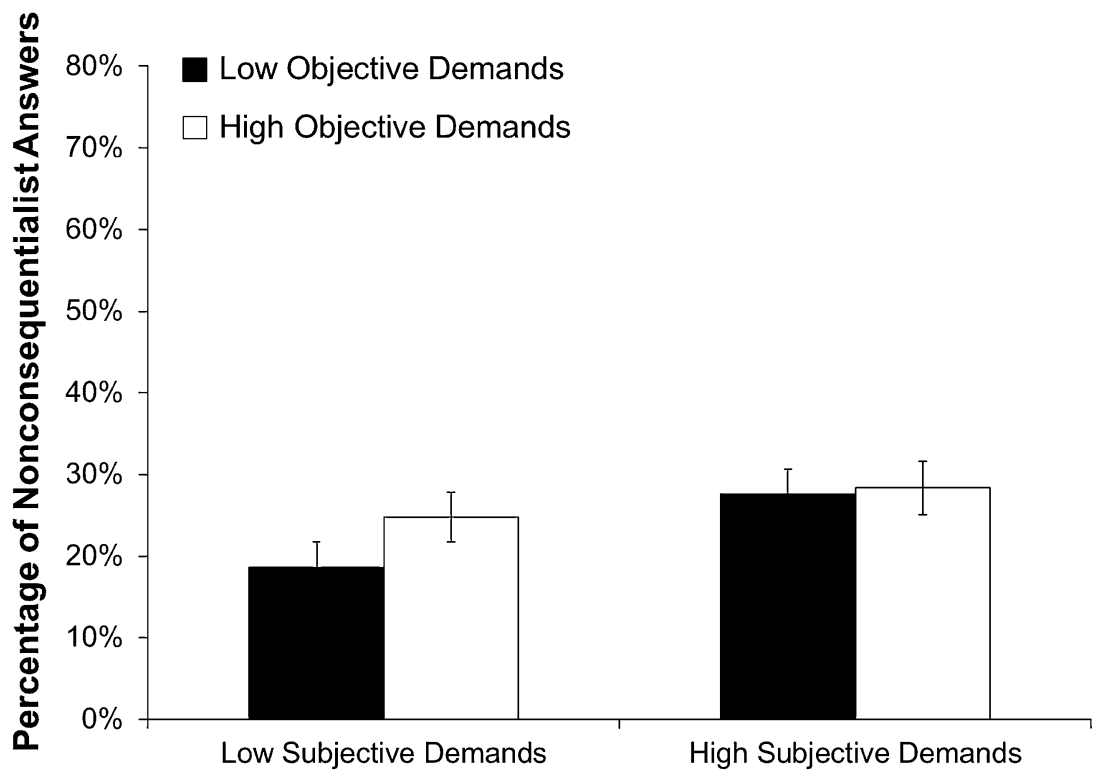

Figure 4 Percentage of nonconsequentialist answers to the overall assessment of reasons relevant to the decision averaged across the six scenarios for each level of objective and subjective demands. This restrictive analysis is limited to those who reported that (a) they had no decisive reason to follow the consequentialist demands and (b) the consequentialist course of action was not demanded by morality. 
high levels of formal schooling. ${ }^{27}$ However, the influence of education was not extremely strong: Averaging across the six scenarios, dissent with consequentialism remained below $57 \%$ in all groups even in the highest demand level. Thus, there was no evidence that the intuition supporting OD occurs in its expected form at least in certain strata of the population (Figure 5).

\section{General Discussion}

Taken together, we suggest that our representative study leads to three key conclusions. ${ }^{28}$ First, in relation to Hypothesis 1 , the more severe the requirements made by consequentialism, the less reason people intuit having for following these requirements. Second, concerning Hypothesis 2, despite this sensitivity to consequentialist demands, the absolute level of dissent with consequentialism is not such that one would talk of a widespread OD-intuition. ${ }^{29}$ This holds for the less restrictive analysis in which we solely focused on judgments of reasonableness, but is even more applicable when placing more severe constraints on respondents' patterns of answers (namely that they not only considered the consequentialist course of action as unreasonable but also as not demanded by morality). In this more restrictive analysis, the percentages were even lower, calling the validity of OD further into question.

The large sample of the current study also allowed us to investigate whether intuitions differed between participants with different characteristics (as Hypothesis 3 predicted). Against the backdrop of a growing literature on the connection between moral reasoning and consequentialism ${ }^{30}$ that states that consequentialist judgments rely on "cognitive" reasoning processes (as compared to deontological judgments which supposedly are more strongly driven by emotional responses), we proposed that less highly educated people would be more likely to have the intuition supporting OD. This was indeed true. People with lower levels of formal education were less likely to report that an overall assessment of reasons would guide them to the consequentialist course of action. However, although this effect was statistically significant and is relevant to discussions concerning the role of moral reasoning in consequentialist moral judgments, the magnitude of the effect was not such that it likely to salvage the case for OD. There is no group in the population (at least not

\footnotetext{
${ }^{27}$ Main effect of education: $F(2,947)=3.49, \quad p=.031, \quad \eta_{\mathrm{p}}^{2}=.007$. Dissent $M_{\text {Low }}=44.9 \%$; $M_{\text {Medium }}=40.1 \% ; M_{\text {High }}=40.0 \%$. Post hoc tests (Bonferroni) revealed marginally significant differences between those with low formal education and the two other groups.

28 These partly overlap with the conclusions of our 'Overdemanding Consequentialism?'. However, the superior quality of the present study lends more credibility to our initial findings and the large sample also allowed us to investigate the moderation of our findings by level of formal education (Hypothesis 3 ).

29 This is admittedly a question of numbers, but other empirical research found agreement of around $90 \%$ of respondents, whereas in our studies the highest such number we can quote is $62 \%$.

30 See e.g., J. D. Greene, S. A. Morelli, K. Lowenberg, L. E. Nystrom, \& J. D. Cohen, 'Cognitive Load Selectively Interferes with Utilitarian Moral Judgment', Cognition 107 (2008), pp. 1144-1154, and J. M. Paxton, L. Ungar, \& J. D. Greene, 'Reflection and Reasoning in Moral Judgment', Cognitive Science 36 (2012), pp. 163-177.
} 


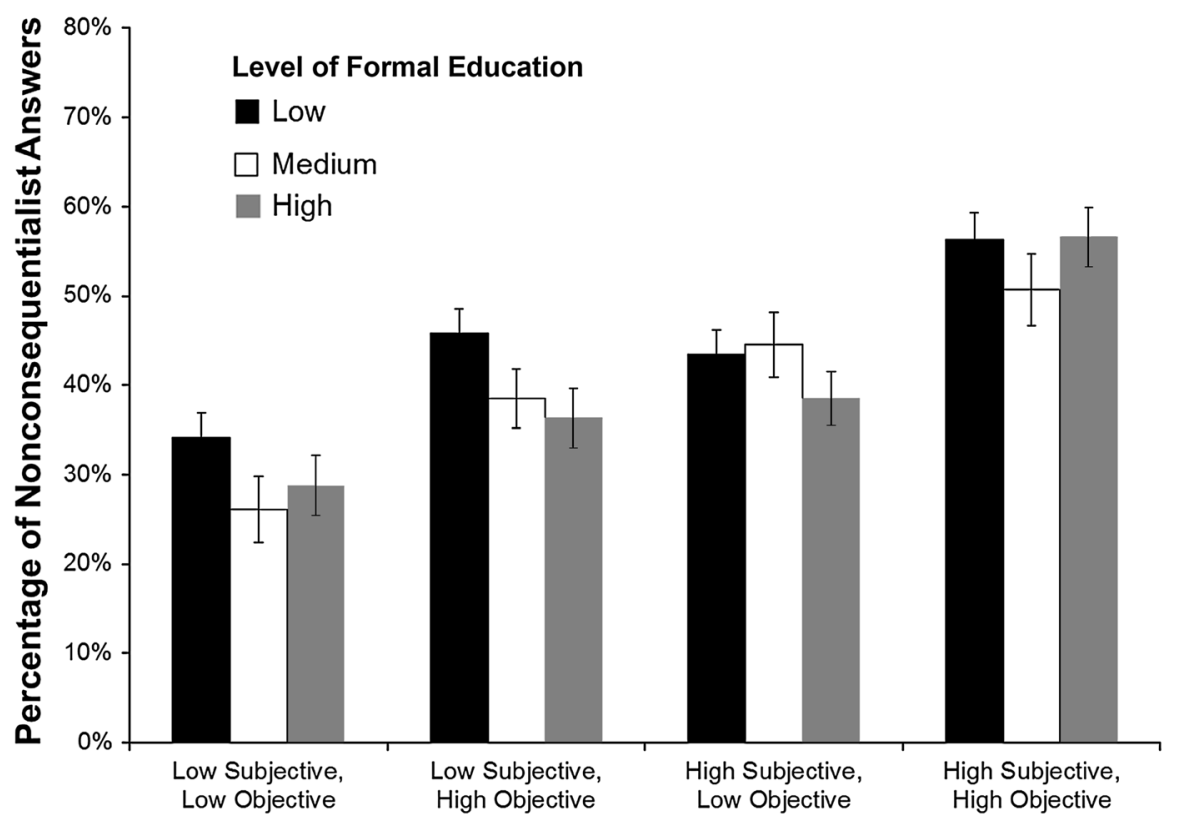

Figure 5 Percentage of nonconsequentialist answers to the overall assessment of reasons relevant to the decision averaged across the six scenarios for each level of objective and subjective demands and for each of three levels of formal education.

one that can be identified by formal level of education) that consistently reports the intuition supporting OD.

Of course, before accepting these conclusions, one may raise a number of critical points about this research: First, there is the issue of the status of intuitions in moral philosophy. How can intuitions constrain normative moral theories? Second, even if intuitions are relevant in moral philosophising, how can we know about them and is the particular study presented suited to revealing them? Third, given the oftenobserved variation in intuitions (more precisely, the variation in empirical observations that claim to correspond with intuitions), there is an issue of whether we need to specify whose intuitions should be assessed. Is a particular qualification needed to have the "right" moral intuitions? Finally, fourth, one may have more specific methodological qualms with the testing of our hypotheses. Even supposing that the prior three issues were resolved, do our studies lead to the conclusions that we draw from them? In the following, we will respond to each of these challenges by pointing out why we answer all of them in the affirmative, but also identifying areas that are prior to or outside of the scope of the present article and areas that our research does not fully address.

Start with the first issue: the use of intuitions in philosophy. The concept of an intuition reflects the idea that there are - practical, theoretical, moral etc. - truths and that people arrive at these truths not primarily through a process of reflection and reasoning, but rather by a more immediate process somewhat akin to 
perception. Hence the significance of intuitions in philosophy: they matter because they are taken to have evidential value. ${ }^{31}$ Like observations in science, intuitions are the raw data that competing philosophical theories should at least try to accommodate, and if empirical research uncovers these intuitions, this is a result that should not be ignored without thorough consideration. Of course, just as almost anything else, the role of intuitions in moral philosophy can be disputed. Scepticism about the evidential value of intuitions can be based on ontological, epistemological, or evolutionary grounds. ${ }^{32}$

However, this debate concerning the status of intuitions is beyond the scope of the present article. More than that: anti-scepticism about the evidential value of intuitions is already presupposed by what we are concerned with here. As we have shown in the introduction, OD includes (and has to include) as a critical premise an empirical claim concerning the existence of a certain intuition that supposedly constrains consequentialist moral theories. If one questions the role of intuitions in moral philosophy, one therefore rejects OD on a basis other than premise (3), which is the one we focus on. Thus, the so-called strategy of extremism defending consequentialism against OD can be supported by rejecting that intuitions have evidential value. But, of course, such an approach is itself contested and it is not our aim in this paper to provide it with support. ${ }^{33}$

Turn to the second issue of whether there is an adequate procedure to learn about people's intuitions and whether we have implemented such a procedure. Detecting intuitions is no easy task, partly because, and this is related to the above problematic, it is far from clear what intuitions are. In addition, it can be pointed out that our research into intuitions simply takes stated opinions at face-value and, the objection goes, it is far from clear that those opinions do indeed qualify as intuitions. We admit to this being a problem. However, this problem does not apply to us alone. Indeed we suggest that experimental philosophy can be, should be, and is continuously challenged on the grounds of whether it really is able to elicit and observe people's relevant intuitions. If one considers it to be impossible in principle to learn what moral intuitions people have, this applies to all empirical research on intuitions. In this case all empirical research, of this type, is doomed to failure in philosophy, and ours, we admit, would be no exception.

\footnotetext{
31 See some of the essays in Truth and Realism, (Oxford: Clarendon, 2006). It can be pointed out, though, that we do not distinguish two different notions of intuitions that seem to be in use: the less demanding notion understands intuitions as the content of untutored common-sense or folk morality, the more demanding and technical notion that we also use in this article, considers intuitions as a sort of immediate cognition. Supposing that these two notions exist, two points in response: First, we doubt that we can indeed make use of the less demanding notion because the epistemological status of such intuitions is unclear at best. Second, by opting for the more demanding notion, we aim to strengthen the implications of our discussion.

32 In moral philosophy recent works include, on the sceptical side, Peter Singer, 'Ethics and Intuitions', The Journal of Ethics 9 (2005), pp. 331-352; on the anti-sceptical side, Folke Tersman, 'The Reliability of Moral Intuitions: A Challenge from Neuroscience', Australasian Journal of Philosophy 86 (2008), pp. 389-405; Matthew Liao, 'A Defence of Intuitions', Philosophical Studies 140 (2008), pp. 247-262.

33 For references see footnote 10. See also Matthew Tedesco ('Intuitions and the Demands of Consequentialism', Utilitas 23:1 (2011), pp. 94-104) who pursues this line further by bringing in neuroscientific evidence.
} 
However, if one thinks that such knowledge is possible in principle, the search for intuitions becomes a question of degree - with its success determined by the quality of the experimental design and the specific procedure of the study. What we want to argue here then is that we have gone to considerable lengths to investigate intuitions in a way that - given the state of knowledge about intuitions and the currently available procedures - offers us a good chance that we do at least as good as others in identifying intuitions. In particular, we have taken great care in designing our questions such that we can differentiate between people's assessment of reasons within a situation, their moral beliefs, and their behaviour or behavioural intentions. Further, by using different procedures on different occasions and finding highly similar patterns of results across both of them, we have shown that the intuitions we elicit are not dependent on the particular format of the study. ${ }^{34}$ In our view, such triangulation across different assessment procedures is key to identifying intuitions. If a particular finding remains stable under different circumstances, this is a strong hint, we would argue, that the finding is indicative of an intuition rather than a variable surface opinion. Such an approach should be developed more fully in the future and we will outline some initial ideas about it in the subsequent section.

The third critical issue concerns our sample of respondents. Even if the methodology is adequate, it goes, the variation in the intuitions we observe may be due to us examining the wrong people. Indeed, there seem to be robust individual differences in moral intuitions. ${ }^{35}$ On this basis, one could, for example, make a distinction between folk intuitions - the ones we deal with - and expert (philosophers') intuitions, hold that only the latter count, and that they are perhaps, uniformly - on the side of OD. However, given the ongoing philosophical debate about OD, it is unlikely that the latter claim holds. Also, it has been argued and found that philosophers' intuitions are susceptible to much the same biases, distortions, and instabilities as lay people's intuitions. ${ }^{36}$ Having said this, we consider this objection to be at least in part an empirical matter and are hoping to run similar studies with philosophers as respondents. At this stage, it seems an open debate whose intuitions matter: those of the experts, those of lay people, or, perhaps, any idiosyncratic intuition? ${ }^{37}$ We have tested one possible answer to this question, namely, that formal level of education is relevant in defining a group of people that consistently holds the OD-intuition, but found our results inconclusive. In this paper we cannot venture beyond this point; therefore, for the moment, we settle with the provisional conclusion that there is at least as much argument speaking in favour of

\footnotetext{
34 In this paper we present one study, but in our 'Overdemanding Consequentialism?' we present the results of three further studies: two scenario studies and a third experimental game in which participants had to make real decisions with real consequences. For further details on these studies see footnotes 40 and 41.

35 Shaun Nichols and Joseph Ulatowski, 'Intuitions and Individual Differences: The Knobe Effect Revisited', Mind and Language 22 (2007), 346-365.

36 See Jonathan M. Weinberg, Chad Gonnerman, Cameron Buckner, \& Joshua Alexander, 'Are Philosophers Expert Intuiters?', Philosophical Psychology 23 (2010), pp. 331-355; Eric Schwitzgebel and Fiery Cushman, 'Expertise in Moral Reasoning? Order Effects on Moral Judgment in Professional Philosophers and Non-Philosophers', Mind \& Language (in press).

37 For a recent position that appears to favour folk intuitions see M. B. E. Smith, 'Does Humanity Share a Common Moral Faculty?', The Journal of Moral Philosophy 7 (2010): 37-53.
} 
investigating folk intuitions as any other intuitions of a defined group of people. However, in ending our paper, we will put forward some ideas on how to handle this problematic in another way by attributing virtue a role in our proposed experimental methodology.

Let us finally turn to concerns about the particularities of our argumentation. One can make several charges at this point. First, one might ask: could it be that the scenarios are so unrealistic and construed that people more easily give 'desirable' answers than in complex real life settings where the influence of one's own actions on the world are less clear and all-or-nothing affairs? Alternatively, second, the objection could be: since Hypothesis 1 is confirmed, that is, we established that increasing demands lead to increasing dissent with consequentialism, we likely would also observe a confirmation of Hypothesis 2 if we considered sufficiently extreme situations. Finally, third, we speak in terms of percentages; however, the objection goes, the empirical premise of OD should be uniformly true (or false) throughout the population. ${ }^{38}$

Let us proceed in order. The first and the second objection pull in opposite directions, hence it is hard to see how they could be advocated together. Considering them individually, the first objection appears unconvincing to us since we do not find our scenarios unrealistic, certainly not when they are compared to other thought experiments in philosophy. Besides, elsewhere we have presented results of an experiment that is more realistic and supports our conclusion in this paper. ${ }^{39}$ To the second objection our primary response is that the force of OD comes from situations that are well embedded in our everyday practice. ${ }^{40}$ Concerning situations that more much more extreme and are accordingly very unlikely to occur, further arguments would be needed to show why such cases would provide adequate basis for an objection that is not conceptual or metaphysical in nature. The third objection we would like to dwell upon a bit further in ending this section.

Our initial reaction is that although philosophical 'purity' might require such a uniform result, in practice striving for it is a doomed enterprise, when it comes to the testing of folk intuitions. Therefore, when speaking of the existence of an intuition in the case under investigation, namely as part of an argument against consequentialism, we decided to follow a statistical approach: for the intuition to be

\footnotetext{
${ }^{38}$ Of course this is only an objection in one respect (namely, that concerning our methodology). In another, that concerning our conclusion, it supports our position: since if uniformity was a sensible requirement, our results would definitely refute OD (not just put its empirical premise into doubt, as we prefer to say).

39 In our 'Overdemanding Consequentialism?', we have presented the results of an experimental game. The goal of this study was to create an actual decision situation with real-life monetary consequences. This was done to investigate the OD-intuition while avoiding the possible adverse effects of the "as if"character of imaginary scenarios. To do so, we adapted a paradigm previously used in behavioural economics: Participants divided a certain sum $(€ 100)$ between themselves and the vaccination program of the United Nations Children's Fund (UNICEF) benefiting children in developing countries. Participants knew that for one randomly determined participant, this choice would be implemented in real.

40 As a secondary response, we note that in a small follow-up study, which also appears in our paper 'Overdemanding Consequentialism?', we affirmed that results that are reported in this paper are largely parallel in cases that have been introduced in the philosophical literature to illustrate the gist of OD. The examples we used were taken from Bykvist, Utilitarianism, pp. 98-99, and Mulgan, Understanding Utilitarianism, pp. 95-96.
} 
useful (and reliable as evidence), it is not enough if only few people have it. It should be shared by a strong majority. ${ }^{41}$ Hence the question is whether this statistical approach is legitimate.

We do think so: percentages matter. On the one hand, intuitive objections like OD appeal to those who have the intuitions in question. Hence the more people have the intuition, the more persuasive the given objection is. On the other hand, as we saw, intuitions are not merely devices of persuasion but have justificatory power: they have the potential to establish the validity of a conclusion because, say, they serve as evidence for the truth of this conclusion. In the absence of any reasonable expectation that we can find uniformity - rejection or acceptance - in people's intuitions, percentages come to play a crucial role. To put it simply: the more people have the intuition in question, the more likely it is that they are getting things right and the validity of the objection can be established. But again: we do not claim that we refute the idea that there exists an OD-intuition. What we claim is that our results provide ground to doubt the existence of this intuition and that there at least seem to be some relevant situations and samples in which it does not clearly reveal itself. Thus, our claim is that our studies challenge proponents of OD to specify the conditions under which the relevant intuition will be apparent.

\section{A New Methodology?}

In this paper we have discussed the empirical premise of what we called the Overdemandingness Objection. The premise claims that certain demands of consequentialism are such that, intuitively, we do not have decisive reason to meet them. In a scenario study that was designed to be representative of the German population we have put this claim under empirical scrutiny and found that there is reason to doubt its truth. This study, however, was limited in a number of ways as has become clear in the above discussion. So the question is: where can we go from here?

We hold that experimental philosophy must strive to become better in gauging intuitions. This requires methodological innovations. The indispensable first step for such innovation is a good account of intuitions. We propose to conceptualise intuitions by focusing on three of their features. ${ }^{42}$ They are immediate, in that they occur "quickly, effortlessly, and automatically, such that the outcome but not the process is accessible to consciousness." 43 They are also non-inferential: they do not

\footnotetext{
${ }_{41}$ As pointed out in the beginning of this section (footnote 30), we are far from being alone with this statistical approach.

42 This might be an overly demanding account of intuitions. To illustrate: philosophers put emphasis on lack of inference and sometimes stability, whereas psychologists tend to single out immediacy as an essential characteristic of intuitions. There is thus some work to be done to see whether all three characteristics are needed. In these final remarks, however, we do not want to - and cannot - settle these substantial questions.

43 Jonathan Haidt, 'The Emotional Dog and Its Rational Tail: A Social Intuitionist Approach to Moral Judgment', Psychological Review 108 (2001), p. 818.
} 
follow inferentially from some moral theory or principle. ${ }^{44}$ Finally, they are stable: they are those immediate and non-inferential responses of the agent that, so to speak, withstand the test of reflection, i.e., a competent speaker would retain them under sufficiently ideal conditions, such as when the speaker is not biased. ${ }^{45}$ Once this account of intuition is at hand, one can start building a methodology for identifying them.

Here the challenge is to develop a methodology that can test all three characteristics without eliminating any of them. While there are well-rehearsed techniques in social psychology to test immediacy, ${ }^{46}$ testing lack of inference usually relies on testing immediacy, which is not satisfactory (since there is no intimate relation between immediacy and lack of inference). Instead, we propose to invoke emotions at this stage. If perceptual theorists of emotion are right, emotions can provide us with non-inferential knowledge of (moral) propositions. ${ }^{47}$ Hence if experimental research can involve the study of emotions in (moral) decision situations, in ways that check elicited 'intuition-candidates' against the relevant emotional responses, we could get a good test for the noninferential character of intuitions. ${ }^{48}$ Finally, the stability of the judgments invoked in the first two phases, can be tested with methods that engage conscious, analytical-rational mental processes to further examine whether the spontaneous, non-inferential judgments stand the 'test of reflection' and therefore acquire the status of intuitions.

A further question the new methodology has to answer has been touched upon earlier. As we noted, it is not clear whose intuitions should be taken seriously: the layman's, the expert's, the philosopher's or any one individual intuition alone? We hold that the best approach would be to identify quality criteria for intuitions. These criteria could tell us something about an intuition's justifying power, i.e. its potential to be used as evidence of (moral) truth. A possible starting point is to gauge an intuition's justifying power by appeal to the bearer of the intuition, the intuitor. Just as there is general agreement that a colour-blind person is not a good informant when it comes to the description of colour differences, some people might lack the individual prerequisites for correct moral intuitions (or to have the correct intuitions with

\footnotetext{
44 Tersman, 'The Reliability of Moral Intuitions'.

45 See Anti Kaupinnen, 'The Rise and Fall of Experimental Philosophy', Philosophical Explorations 10 (2007), pp. 95-118, on robust vs. surface intuitions.

46 E.g., R. W. Holland \& M. de Vries, 'Implicit Evaluation as a Basis for Intuition', in A. Glöckner \& C. Witteman (eds.), Foundations for Tracing Intuition: Challenges and Methods, (New York: Psychology Press), pp. 123-138.

47 For this claim see, e.g., Sabine Döring, 'Seeing What to Do: Affective Perception and Rational Motivation', Dialectica 61 (2007), pp. 363-394. Going one step further, Sabine Roeser, Moral Emotions and Intuitions, (Basingstoke: Palgrave Macmillan, 2011), identifies emotions with intuitions.

48 Admittedly, this is a contentious claim. To mention two of the questions that will have to be dealt with: one, we will have to specify which emotions we are going to use, and two, we will have to show that these particular emotions elicit non-inferential knowledge and not inferential knowledge (this is an issue of course, only if it is not the case that all emotions elicit such knowledge).
} 
a high probability). Put positively, some people might be particularly apt intuitors. $^{49}$

More specifically, we propose to differentiate the justifying power of intuitions using a virtue ethics approach. The two major themes of such an approach revolve around moral character and moral education. Thus, these themes relate to the questions 'What characteristics does someone necessarily have to possess to be considered a moral person?' and 'How can a person acquire moral character?' Despite the apparent focus on the individual moral agent, Rosalind Hursthouse has argued that a virtue ethics approach focusing on moral character can also provide specific action guidance. ${ }^{50}$ The question then becomes how a virtuous agent however virtues are understood - has moral knowledge of what constitutes right action. In line with the intuition-centred approach adopted throughout this proposal, the answer, we suggest, lies in the virtuous agent having true moral intuitions. The virtuous person must be a virtuous intuitor. Our proposal is that what constitutes a virtue and the truth assigned to moral intuitions about specific actions stand in a close relationship, such that moral agents will assign differing justificatory power to intuitions depending on whether they believe the intuitor possesses a virtue (and vice versa).

It is, no doubt, a notoriously difficult matter to give an account of the virtues one is looking for in a way that avoids collapsing back into circularity (because to understand what virtues are, there is danger that one (also) has to make use of one's intuitions about what is good and bad). However, what the above does, at a minimum, is give us a theory concerning the relationship between two kinds of intuitions which we label action-intuitions (i.e., intuitions about the moral value of specific actions) and virtue-intuitions (i.e., intuitions about which character traits constitute moral virtues). ${ }^{51}$ Although the distinction between action-intuitions and virtue-intuitions will not directly lead us to an account of which/whose intuitions to trust, it offers us the possibility of triangulation as a method to assess the consistency of intuitions across the domains of virtue and action. If intuiting is indeed based on a single competence then intuitions concerning actions and concerning virtues should be consistent. If they are not, this will, all else being equal, shed doubt on the justifying power of such intuitions.

\footnotetext{
49 See E. Sosa, 'Experimental Philosophy and Philosophical Intuition', Philosophical Studies 132 (2007), pp. 101-102. Such an approach focusing on competence or expertise in moral judgment, on the one hand, and intuitions, on the other, fits well with newer social-cognitive approaches in moral psychology. See, e.g., D. K. Lapsley \& D. Narvaez, 'A Social-Cognitive Approach to the Moral Personality', in D. K. Lapsley \& D. Narvaez (eds.), Moral Development, Self and Identity, (Mahwah, NJ: Erlbaum, 2004), pp. 189-212. These approaches also suggest that moral competencies can be successfully developed and taught. See e.g., D. K. Lapsley \& F. C. Power, Character Psychology and Character Education, (Notre Dame, IN: University of Notre Dame Press, 2005).

50 In her On Virtue Ethics, (New York, NY: Oxford University Press), esp. pp. 28-29.

51 The empirical investigation of such common intuitions concerning virtues has become a major research area both in moral (J. Haidt \& S. Kesebir, 'Morality', in S. Fiske \& D. Gilbert (eds.), Handbook of Social Psychology, (Hoboken, NJ: Wiley, 2010), pp. 797-832) and positive (J. Shryack, M. F. Steger, R. F. Krueger, \& C. S. Kallie, 'The Structure of Virtue: An Empirical Investigation of the Dimensionality of the Virtues in Action Inventory of Strengths', Personality and Individual Differences (2010), pp. 714-719).
} 
The next step of this part of our proposed methodology would be to bring emotions into the equation. Once again, perceptual theories of emotion can be of help here. However, the link between emotions and intuitions is worked out in more detail than the relationship between virtues and either of the other two. This part of the proposed methodology should therefore tell us not only how virtue-intuitions and action-intuitions are related but also by detailing how emotions, as a further source of information, can help in the triangulation process. In our context this would mean that it would be fair to judge the justifying power of the OD-intuition as reduced not only if the intuitor simultaneously holds an incompatible virtueintuition, but also (over and above this) if s/he experiences emotions that are not in line with the intuition underlying OD.

These are, of course, only sketchy remarks. Nevertheless, we believe that the proposed methodological approach to detecting intuitions and establishing their justifying power positively transcends the strong reliance of research in experimental philosophy and moral psychology on self-reports of (moral) judgments. The suggested multi-method approach would therefore increase our understanding of the intuitive processes involved in judging the overdemandingness of consequentialist requirements in particular and in making (moral) judgments more generally. And to achieve this would already significantly advance empirical research responding to philosophical challenges within philosophy and beyond.

Acknowledgments We would like to thank audiences in Konstanz, the Hague, Nottingham, Bayreuth, and Lucca, as well as all those who have commented on prior versions of the manuscript. This particularly applies to the editors of the present volume, Sabine Roeser and Joel Rickard. The research reported in this paper was funded by several grants from the Zukunftskolleg at the University of Konstanz. It was also supported by a grant to Attila Tanyi from the German Research Foundation (Grant number: TA 820/1-1). 